\title{
A Construção de Jogos Digitais na Escola: um Relato de Experiência na Formação de Professores
}

\author{
Gláuber Galvão de Araujo ${ }^{1}$, Thiago Reis da Silva ${ }^{1,2}$, Eduardo Aranha ${ }^{1}$ \\ ${ }^{1}$ Programa de Pós-Graduação em Sistemas Computacionais - PPgSC \\ Universidade Federal do Rio Grande do Norte - UFRN \\ Campus Universitário Lagoa Nova -Natal/RN - Brasil \\ Laboratório Gamedu.net \\ ${ }^{2}$ Instituto Federal de Educação, Ciência e Tecnologia do Maranhão - IFMA \\ glauber.galvao@gmail.com, thiago.reis@ifma.edu.br, \\ eduardoaranha@dimap.ufrn.br
}

\begin{abstract}
This paper presents the conduction and evalution of a teachers formation experience of basic education in Rio Grande do Norte's public network schools for using initial steps of the Game Design in order to create games as support for the teaching and learning process. The teachers involved could think over about the impact of utilization of this innovative process inside classroom, exercising in practice a games' concept definition as solution for presented problems in a workshop led by researchers.
\end{abstract}

Resumo. Este artigo apresenta a condução e avaliação de uma experiência de formação de professores do ensino básico da rede pública do estado do Rio Grande do Norte para a utilização de etapas iniciais do Game Design para a criação de jogos digitais como apoio ao processo ensino e aprendizagem. Os professores participantes puderam refletir sobre o impacto da utilização desse processo inovador dentro da sala de aula, exercitando na prática a definição de um conceito de jogo como solução a problemas apresentados em uma oficina conduzida pelos pesquisadores.

\section{Introdução}

Muito se discutiu acerca da Educação nas últimas décadas e o resultado são algumas políticas públicas e várias ações isoladas não-governamentais que tentam reduzir o déficit quantitativo e qualitativo de anos com avanços acanhados. As salas de aulas ainda são as mesmas do século passado, mesmo com a inserção das novas Tecnologias da Informação e Comunicação (TIC), propagadas como solução para os problemas no processo ensino e aprendizagem. Mas, a tecnologia sozinha não soluciona problemas sem a inteligência e o manuseio hábil daqueles que estão diante dos alunos todos os dias, os professores.

Dentre as várias propostas de contribuições para a melhoria do processo ensino e aprendizagem, a utilização de jogos digitais talvez seja uma das mais inovadoras, mas também a que mais contrapõe o modo convencional de trabalhar conteúdos, competências e habilidades em sala de aula, devido a sua natureza de entretenimento e diversão. Afinal, entretenimento e diversão eram elementos inadmissíveis nas salas de aulas do passado. 
Segundo Mattar [2010], jogar "desenvolve a capacidade de deduzir regras pela observação e manipular sistemas complexos, características essenciais para o trabalho em ciências". A atenção e o raciocínio lógico, principalmente em jogos de estratégia, são também elementos estimulados com o uso de jogos digitais. $\mathrm{O}$ exercício da atenção nos jogos provoca a imersão do jogador e um estado de extrema concentração na tarefa que está desempenhando.

Nesse sentido, o uso de jogos digitais em Educação é uma das possibilidades para explorar o potencial das crianças desse século, possibilitando a elas aprender enquanto brincam com identidades, assumindo e construindo diferentes personalidades virtuais nos jogos. Algumas vezes essa identidade pode ser a de um detetive que soluciona enigmas e resolve casos de investigação [Mattar 2010], em outro momento um viajante no tempo que interage com a história.

Com todos esses aspectos positivos, os jogos digitais têm despertado o interesse da comunidade científica e tornaram-se objetos de pesquisa, como instrumentos de aprendizagem em diversas áreas do conhecimento, como, Pedagogia [Pietruchinski et. al., 2011], Ensino de Computação [Silva et. al., 2015], dentre outros.

Neste artigo, será apresentada uma experiência na formação de professores do Ensino Básico da rede Estadual e Municipal de ensino do Rio Grande do Norte (RN), realizada no contexto do programa Mais Educação, que teve como objetivo sensibilizar os participantes para a utilização de processos de desenvolvimento de jogos digitais nas escolas de tempo integral, a partir das técnicas do Game Design. O Programa Mais Educação, constitui-se como estratégia do Ministério da Educação para induzir a ampliação da jornada escolar e a organização curricular na perspectiva da Educação Integral.

Sendo assim, criar mecanismos de coletar o feedback dos participantes e realizar análise dessas impressões foram de fundamental importância para a verificação do atingimento dos objetivos propostos. Nesta perspectiva, foram realizadas 9 oficinas com o envolvimento de 229 professores em diferentess cidades do RN. Além de descrever a realização das oficinas e seus resultados, o estudo avaliou o feedback dos participantes no que diz respeito, entre outras coisas, ao nível de satisfação com as atividades, pontos fortes e fracos da temática e o potencial da replicação das oficinas nas escolas.

Portanto, este trabalho está organizado na seguinte forma: na Seção 2 é apresentada o Game Design, a Seção 3 apresenta a metodologia das oficinas, a Seção 4 apresenta os resultados das oficinas, a Seção 5 detalha o feedback participantes e, por fim, a seção 6 é faz as conclusões finais e apresenta as perspectivas de trabalhos futuros.

\section{Game Desing}

O Game Design é para o jogo digital o que a planta baixa é para a construção de uma casa [Schuytema 2008]. Antes dos tijolos, cimento, areia, telhas e material de acabamento, precisa de uma planta baixa para dimensionar a construção de um edifício. Nesse sentido, antes da programação do jogo digital, há uma etapa de fundamental importância composta de processos que definem o novo jogo digital. 
O Game Design é o ato de decidir o que um jogo digital deve ser [Schell 2011], é o processo de projetar, elaborar regras, criar mecânicas, definir enredos, ou seja, especificar claramente as características de um jogo digital.

Para Schell [2011], o Game Design deve conter soluções para os elementos básicos de um jogo digital, quais sejam: (a) Mecânica, os procedimentos e regras; (b) Narrativa, a sequência dos eventos; (c) Estética, a aparência, sons e sensações e; (d) Tecnologia, os materiais e interações.

O jogo digital, como artefato resultante de um processo criativo, é criado a partir de um ciclo de desenvolvimento que compreende três etapas: (1) Pré-produção, no qual o conceito do jogo digital é definido; (2) Produção, no qual ocorre a construção do jogo digital e a campanha de marketing para a distribuição do jogo digital e; (3) Pósprodução, no qual são incluídos adicionais ao pacote do jogo digital e avaliações do produto pronto e sua distribuição.

O Game Design utiliza as soluções apresentadas na etapa de pré-produção e inicia o processo produtivo com as definições presentes nos documentos de Design como o Game design Document (GDD). Esse documento, que pode conter poucas a inúmeras páginas, orienta as equipes que participam do desenvolvimento do novo jogo digital.

\section{Metologia das Oficinas}

Foram realizadas 9 oficinas de Game Design (conforme Tabela 1) com um público participante composto por professores do Ensino Básico de vários municípios do estado do RN, que atuam em escolas de tempo integral do programa Mais Educação.

Tabela 1 - Detalhamento das oficinas.

\begin{tabular}{|c|c|c|}
\hline Oficinas & Cidades & Participantes \\
\hline Oficina 1 & Mossoró - RN & 30 \\
\hline Oficina 2 & Natal - RN & 34 \\
\hline Oficina 3 & Natal - RN & 20 \\
\hline Oficina 4 & João Câmara - RN & 30 \\
\hline Oficina 5 & Parnamirim - RN & 25 \\
\hline Oficina 6 & Santa Cruz - RN & 25 \\
\hline Oficina 7 & Pau dos Ferros - RN & 22 \\
\hline Oficina 8 & Assú - RN & 23 \\
\hline Oficina 9 & Caicó - RN & 20 \\
\hline \multicolumn{2}{|c|}{ Total de Participantes } & $\mathbf{2 2 9}$ \\
\hline
\end{tabular}

As oficinas, intitulada "Game Design - concepções e processos básicos" apresentaram aos participantes os conceitos fundamentais da área, explorando as concepções de jogos digitais e de como desenvolvê-los. Cada uma das 9 oficinas teve 4 horas de duração, totalizando 36 horas de oficinas.

\subsection{Método de Concepção}

O método utilizado para a concepção das oficinas adotou as seguintes fases [Silva, Araujo e Aranha 2014]: 
- Levantamento bibliográfico: realizou-se um levantamento bibliográfico, contemplando os processos de desenvolvimento de jogos digitais e a sua aplicação prática no ambiente escolar;

- Planejamento e preparação das oficinas: preparação dos recursos didáticos a serem utilizados em aulas expositivas e as atividades a serem realizadas na prática, considerando: (i) tempo de 4 horas destinado às oficinas; e (ii) desconhecimento do assunto por parte da maioria dos professores participantes;

- Aplicação das oficinas: execução das oficinas em laboratório de informática durante um único dia, com carga horária de 4 horas de duração. Os participantes foram instruídos sobre conceitos e abordagens de Game Design, bem como o passo a passo do processo de criação de um conceito de jogo. Em seguida, foram disponibilizados para os participantes, papel, cartolina, pincel, lápis e tesoura, para que proponham um conceito de jogo documentado em uma Página-Única utilizando o processo de Game Design como resposta a um problema apresentado pelo instrutor;

- Seminário de resultados: os participantes, organizados em grupos, após aplicarem o processo do Game Design para definir um conceito de jogo, apresentaram suas soluções documentada por meio de apresentação oral em um seminário; e

- Questionário e análise de avaliação da oficina: ao final de cada oficina foram aplicados questionários de avaliação da oficina com os participantes. Os resultados obtidos foram analisados. (Definir objetivos do questionário)

\subsection{Execucação das Oficinas}

As oficinas foram conduzidas por um professor que apresentou o conteúdo e explicou as atividades a serem realizadas. Durante a execução das atividades, dois instrutores deram apoio aos participantes, esclarecendo as dúvidas e orientando na execução dos processos do Game Design.

As atividades ocorreram em três momentos: (i) teoria; (ii) prática e; (iii) seminário. No primeiro momento, foram apresentadas as concepções e conceitos fundamentais da área de jogos, especialmente de jogos digitais e dos processos do Game Design, bem como a sua relação com práticas inovadoras aplicadas à educação. $\mathrm{Na}$ segunda etapa, os participantes, organizados em grupos, passaram a desenvolver o processo do Game Design para problematização e busca de soluções, visando a definição de um conceito de jogo com fim educativo. O resultado dessa etapa foi à elaboração de um documento Página-Única com o detalhamento do conceito de um jogo. Na terceira e última etapa, os grupos apresentaram o resultado do seu processo em um seminário. As oficinas seguiram a seguinte dinâmica:

- Introdução aos jogos digitais e ao seu processo de criação: foi apresentado o propósito da oficina e os conceitos relacionados a jogos digitais e seu processo de desenvolvimento com atenção ao Game Design e seus processos;

- Orientações para a definição de um conceito de jogo utilizando os processos do Game Design: foi apresentado um passo a passo do processo criativo do 
conceito de jogo dentro do Game Design. O passo a passo aplicado foi: (i) Formulação do problema; (ii) Compreensão do problema; (iii) Sessão de Brainstorming para definição de soluções; (iv) Descrição da melhor solução; (v) Refino da melhor solução; (vi) Elaboração do GDD através do Página-Única;

- Prática para os professores: a partir das orientações da fase anterior, foi solicitado aos participantes que criassem um conceito de jogo a partir da compreensão de um problema e em seguida apresentassem a sua solução em um seminário. Após as apresentações, os participantes votaram nas melhores soluções; e

- Avaliação dos resultados: ao final das oficinas foi distribuído um questionário entre os participantes, com o objetivo de verificar os resultados e as opiniões dos participantes sobre as oficinas. Esses resultados e análises estão descritos na próxima seção. delas.

A Tabela 2 detalha as atividades realizadas e o tempo utilizado para cada uma

Tabela 2: Cronograma das atividades realizadas.

\begin{tabular}{|c|l|}
\hline $\begin{array}{c}\text { Tempo da } \\
\text { atividade }\end{array}$ & \multicolumn{1}{c|}{ Ações } \\
\hline 50 minutos & Conceitos: (i) Jogos digitais; (ii) Jogos na educação; (iii) Game Design. \\
\hline 40 minutos & Problematização: Formulando e compreendendo o problema. \\
\hline 25 minutos & Sessão de Brainstorming. \\
\hline 20 minutos & Solução: Escolha da melhor ideia, detalhamento e refinamento. \\
\hline 20 minutos & $\begin{array}{l}\text { Elaboração do documento de Game Design com o detalhamento do conceito de jogo } \\
\text { escolhido em Página-Única. }\end{array}$ \\
\hline 50 minutos & Apresentação das propostas de Game Design. \\
\hline
\end{tabular}

\section{Resultados}

A oficina possibilitou aos participantes conhecerem noções básicas sobre jogos digitais e o seu processo de criação, além de refletirem sobre a viabilidade do seu uso nas escolas e de como replicar o conhecimento para outros professores e alunos. Em relato, os professores vislumbraram a possibilidade de as atividades desenvolverem nos estudantes habilidades e competências como criatividade, raciocínio lógico, trabalho em equipe, responsabilidade e cooperação, o que pode contribuir no desempenho em outras disciplinas.

\subsection{Soluções Apresentadas Utilizando o Processo de Game Design}

Um problema foi definido pelo instrutor da oficina, para que os participantes apresentassem uma solução utilizando o processo do Game Design. O problema compreendia: "Criar um jogo para adolescentes, que trabalhasse habilidades em componentes curriculares do Ensino Básico, como Português, Matemática, História, Geografia, entre outros". Na Tabela 3, são apresentadas duas das soluções propostas pelos grupos. Estas propostas foram as escolhidas por todos os participantes como as melhores dentre todas apresentadas.

O modo como os participantes analisaram o problema apresentado e o modo criativo como pensaram nas soluções demonstraram que a etapa de definição de 
conceito de jogo explorou as reminiscências dos professores no tempo de infância, quando criavam brincadeiras e jogos entre amigos. Durante as atividades, percebeu-se uma descontração e muita liberdade para criar. O envolvimento de todos também foi observado, mesmo daqueles mais tímidos.

Tabela 3: Problemas e Soluções - o conceito do jogo.

\begin{tabular}{|c|c|}
\hline Título: De olho no Look & Título: Dividindo as Latitudes e Longitudes \\
\hline $\begin{array}{l}\text { Público-alvo: Estudantes na faixa etária de } 14 \text { a } \\
17 \text { anos. } \\
\text { Área: Língua portuguesa - tempos verbais. } \\
\text { Jogo: As figuras animadas de menino e menina } \\
\text { vestidos com várias peças de roupas são } \\
\text { exibidas no computador. Jogam meninos contra } \\
\text { meninas. Os jogadores, organizados em grupos } \\
\text { de meninos e meninas, jogam em turno e cada } \\
\text { grupo deve cantar uma música que contenha um } \\
\text { verbo no tempo verbal solicitado por meio de } \\
\text { sorteio no jogo. O grupo que não conseguir } \\
\text { acertar o tempo verbal perde e uma peça de } \\
\text { roupa da figura do gênero perdedor é retirada. } \\
\text { Do mesmo modo, o grupo que acerta a música } \\
\text { com o verbo tem o direito de retirar uma peça } \\
\text { de roupa da figura do grupo oponente. } \\
\text { Objetivo: Ganha os jogadores que conseguirem } \\
\text { retirar todas as peças de roupas da figura } \\
\text { (menino ou menina) do adversário até ficar } \\
\text { somente a roupa de baixo. }\end{array}$ & $\begin{array}{l}\text { Público-alvo: Estudantes na faixa etária de } 10 \text { a } \\
14 \text { anos ( } 5^{\circ} \text { e } 6^{\circ} \text { anos). } \\
\text { Área: Geografia e Matemática. } \\
\text { Jogo: Dividir a turma em dois grupos. Os } \\
\text { jogadores estão perdidos em uma floresta } \\
\text { deserta, cada grupo em uma ponta da floresta. } \\
\text { Por meio de dicas com latitudes e longitudes, o } \\
\text { grupo deverá seguir até um castelo na floresta, } \\
\text { onde encontrarão ajuda. Para avançar nas fases } \\
\text { do jogo, os grupos precisam resolver alguns } \\
\text { cálculos matemáticos utilizando pedrinhas. Ao } \\
\text { resolver o cálculo, o grupo tem direito a uma } \\
\text { dica sobre o percurso que devem trilhar para } \\
\text { chegar ao destino (coordenadas). } \\
\text { Objetivo: O grupo deve chegar ao castelo } \\
\text { localizado em um determinado ponto da floresta } \\
\text { utilizando as coordenadas de latitude e } \\
\text { longitude. Será ganhador o grupo que conseguir } \\
\text { chegar primeiro ao castelo. }\end{array}$ \\
\hline
\end{tabular}

\subsection{Avaliação das Soluções}

As propostas de conceitos de jogos demonstraram o conhecimento dos participantes acerca das características do público-alvo, estudantes adolescentes, e de seus interesses. Desse modo, com o objetivo de avaliar as soluções propostas, foi realizada uma análise das soluções apresentadas levando em consideração a sua viabilidade de desenvolvimento. A finalidade da análise, além de verificar a viabilidade das propostas, também era de verificar se os professores conseguiram assimilar e compreender os conceitos do Game Design.

Nesse sentido, os professores conseguiram compreender o propósito das oficinas, aplicando de forma correta os passos indicados pelo instrutor para pensarem no problema e em como solucioná-lo utilizando os processos do Game Design, com vistas a transformar a proposta em um jogo digital. Foram capazes de criar propostas de soluções viáveis com as novas técnicas aprendidas, que são factíveis de implantação nas escolas onde trabalham.

Conclui-se que as soluções apresentadas trouxeram contribuições importantes sobre como os professores podem intervir no ensino aplicando formas inovadoras que estimulam os alunos a aprenderem. Neste sentido, a experiência mostrou-se valorosa, identificando que a oficina é uma maneira viável de aplicar os processos de desenvolvimento de jogos digitais nas escolas, visto que os professores conseguiram compreender o seu propósito, afirmando que a viabilidade da aplicação das oficinas é possível. 


\section{Feedbacks dos Participantes}

Para verificar se as atividades foram bem sucedidas, foram monitorados $\mathrm{o}$ comportamento e a aprendizagem dos participantes durante as atividades e ao final das oficinas foi aplicado um questionário de avaliação com 12 perguntas. Os participantes avaliaram, entre outras coisas, o seu nível de conhecimento, dificuldades encontradas, interesse pela replicação da oficina em suas escolas e satisfação em relação à oficina. Dos 229 professores participantes, um total de 181 responderam ao questionário. Por se tratar de uma representação de 79,03\% dos participantes em todos os municípios, a avaliação foi considerada relevante.

Os resultados foram classificados em cinco grupos: (i) avaliação inicial, com questões iniciais sobre conhecimento anterior a realização da oficina, intenção em replicar o conhecimento e infraestrutura da escola; (ii) avaliação da satisfação dos participantes com o novo conhecimento; (iii) avaliação dos pontos fortes e fracos das oficinas na visão dos participantes; e (iv) avaliação da confiança dos participantes em aplicar os novos conhecimentos nas escolas onde trabalham.

\subsection{Avaliação Inicial}

Quando questionados sobre o nível de conhecimento sobre Game Design, 86\% dos participantes disseram que não tinham conhecimento sobre o tema, além disso, depois da realização da oficina, 94\% mencionaram o interesse de aplicar a oficina nas escolas (ver Tabela 4). Quando questionados sobre a estrutura das escolas para a aplicação das oficinas, $80 \%$ responderam que a escola possui estrutura, enquanto outros $20 \%$ relataram a falta de estrutura para as oficinas, por exemplo, laboratórios de computadores com máquinas quebradas e falta de programas para o desenvolvimento de jogos. Entretanto, a oficina de Game Design pode ser utilizada em sala de aula convencional, sem o uso de computadores.

Tabela 4: Resultado do questionário de avaliação com os participantes.

\begin{tabular}{|l|c|c|}
\hline \multirow{2}{*}{ Perguntas } & \multicolumn{2}{c|}{ Respostas } \\
\cline { 2 - 3 } & Sim & Não \\
\hline Você tem conhecimentos sobre game design? & $14 \%$ & $86 \%$ \\
\hline Você pretende aplicar essa oficina na escola? & $94 \%$ & $6 \%$ \\
\hline Sua escola tem estrutura para executar a oficina? & $80 \%$ & $20 \%$ \\
\hline
\end{tabular}

Mediante as respostas dos participantes, melhoramos o nível de conhecimento dos professores acerca do processo de desenvolvimento de jogos digitais, há motivação e infraestrutura para a adoção das práticas nas escolas.

\subsection{Avaliação da Satisfação}

Em relação ao nível de satisfação dos participantes com as oficinas, observou-se que a maioria ficou satisfeita com a sua realização (Figura 1a): 69\% dos participantes relataram estarem satisfeitos com as oficinas, $19 \%$ muito satisfeitos, $11 \%$ pouco satisfeitos e $1 \%$ não satisfeitos. Os $12 \%$ de insatisfação foram atribuídos ao pouco tempo das oficinas, como relatam alguns participantes nas avaliações seguintes, que não foi suficiente para suprir o desconhecimento sobre o desenvolvimento de jogos digitais e consequentemente preparar alguns participantes com uma nova técnica. 
Em outro questionamento, sobre o nível de contribuição da oficina para a formação dos participantes (Figura 1b): $65 \%$ dos participantes relataram uma boa contribuição para sua formação, $30 \%$ contribuiu totalmente e apenas $5 \%$ relataram que foi pouca a contribuição para sua formação. Nenhum participante relatou que a oficina não contribuiu para a sua formação, o que demonstra que a oficina mudou algo em relação ao conhecimento sobre Game Design e jogos digitais. Portanto, mesmo com $12 \%$ de insatisfação, todos os participantes informaram que algo do que foi transmitido foi apreendido e contribuiu de alguma forma para a sua formação.

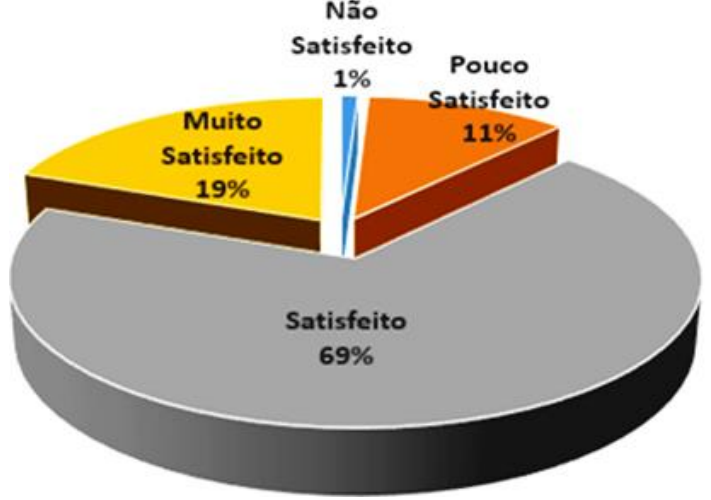

(a)

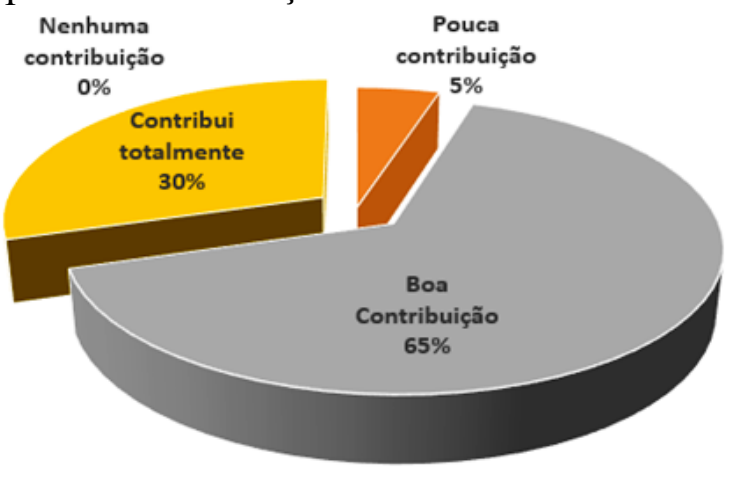

(b)

Figura 1: (a) nível de satisfação com a oficina e (b) nível de contribuição da oficina.

\subsection{Avaliação dos Pontos fortes e Fracos}

Foram direcionadas duas questões discursivas para que os participantes expressassem sua opinião sobre os pontos fortes e fracos das oficinas. Muitas respostas foram semelhantes no sentido do que queriam dizer, e por esse motivo foram agrupadas. A seguir são relacionados os grupos de respostas que expressam o mesmo sentido da maioria das respostas dos participantes para os pontos fortes e fracos observados durante as oficinas.

Os pontos fortes elencados foram: a proposta de produção de jogos nas escolas estimula a criatividade; Game Design é uma inovação para as escolas; trabalhar com jogos incentiva novas descobertas; liberdade para construir nossos próprios jogos; cria oficinas com baixo custo para aplicar nas escolas; e possibilidade de fazer novos jogos de acordo com a realidade e as necessidades dos alunos.

O pouco tempo da oficina, a pouca familiaridade com o planejamento, o desenvolvimento de jogos digitais e com a informática e, ainda, as dificuldades de deslocamentos de alguns participantes para os locais das oficinas, foram os pontos negativos informados. Será necessário estender a carga horária das próximas edições, visto que os participantes têm pouco conhecimento sobre jogos digitais e dos fundamentos de informática.

Como ponto positivo, ficou clara a aceitação da ideia de desenvolver jogos digitais nas escolas como uma atividade inovadora que pode melhorar o processo ensino e aprendizagem. No que tange às sugestões, os participantes, em sua maioria, sugeriram uma carga horária maior para a oficina, uma vez que o assunto é estimulante e que eles tinham desconhecimento desse assunto. Um determinado professor respondeu assim: 
V Congresso Brasileiro de Informática na Educação (CBIE 2016)

Anais do XXII Workshop de Informática na Escola (WIE 2016)

"Que o tempo fosse maior para esta oficina tendo em vista que a mesma é de extrema importância para os alunos, tornando as aulas mais proveitosas".

\subsection{Avaliação em Confiança em Replicar}

Outro questionamento aplicado aos participantes quis saber qual o seu nível de conhecimento sobre a aplicação do processo de Game Design nas escolas em que trabalham. Conforme demonstrado na Figura 2, verifica-se que $28 \%$ dos participantes responderam que sabiam o básico da aplicação, 32\% dos participantes responderam que conseguiriam aplicar esta oficina com assistência de um monitor, 24\% responderam que tinham uma vaga noção de como implantar e $8 \%$ responderam que conseguiriam aplicar esta oficina sem assistência de um monitor.

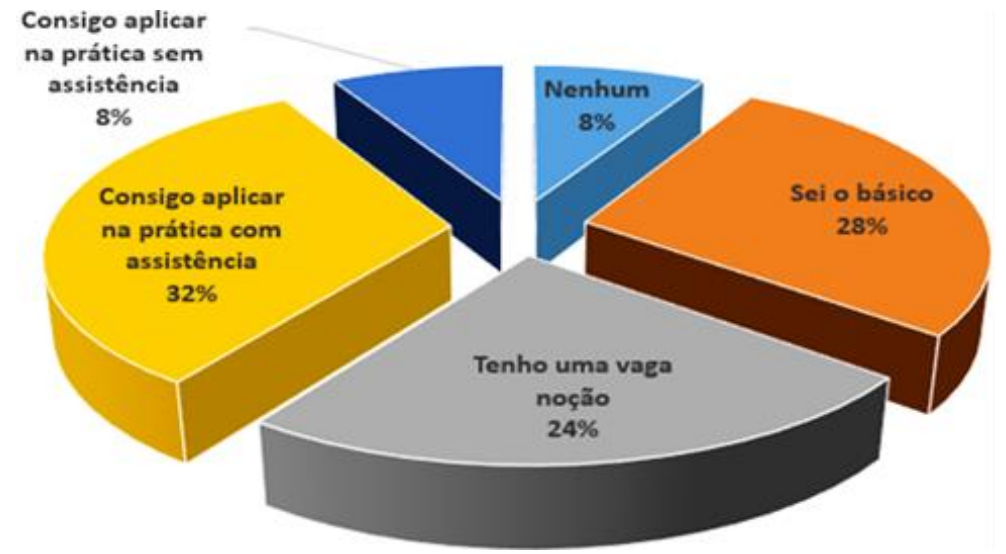

Figura 2: Nível de conhecimento pessoal após a realização da oficina.

Um dado chamou a atenção dos pesquisadores, o fato de $32 \%$ dos participantes informar que seu conhecimento sobre a aplicação dos conhecimentos na escola, mesmo depois da oficina, é "nenhum" ou "tenho uma vaga noção". Diferente do questionamento sobre satisfação, a questão sobre a aplicação do conhecimento aprendido reflete a confiança do participante em replicar o conhecimento para outras pessoas. Nesse sentido, uma parcela expressiva de participantes, mesmo satisfeita com as oficinas e concordando com o fato de elas contribuírem de algum modo com a sua formação, não se sente segura em aplicar as técnicas de desenvolvimento de jogos digitais em sua escola, mesmo com apoio técnico.

\section{Considerações Finais e Trabalhos Futuros}

O relato presente neste trabalho demonstrou uma experiência de sensibilização de professores e coordenadores do Ensino Básico da rede pública do estado do Rio Grande do Norte, atuantes no programa Mais Educação do Governo Federal Brasileiro, para a utilização de processos de criação de jogos digitais em escolas de tempo integral, como apoio no processo ensino e aprendizagem.

Foram propostas oficinas nas quais os professores participantes puderam aprender sobre os fundamentos do desenvolvimento de jogos digitais, além de praticar a definição do conceito de jogo utilizando os processos do Game Design e refletir sobre os ganhos e dificuldades para a implantação desses processos nas escolas. Estas oficinas podem ser utilizadas não só para iniciar o trabalho de preparação dos professores, como 
também servir de base para ser utilizada pelos próprios professores para realizar o Game Design de jogos digitais com fins educativos junto a seus alunos.

Sobre os ganhos, os professores perceberam que a utilização dos processos de criação de jogos digitais pode estimular o uso da lógica computacional, a organização e colaboração em grupos para o desenvolvimento de projetos, bem como engajar os estudantes em assuntos trabalhados no Ensino Básico. Essas competências contribuem com o desempenho do aluno de maneira ampla, envolvendo várias áreas do conhecimento.

Este trabalho, apesar de refletir um estudo pontual, evidencia a forte possibilidade de se trabalhar com o desenvolvimento de jogos digitais nas escolas, especialmente nas escolas de tempo integral. Sobre os aspectos, grau de dificuldade e duração das oficinas, avaliados pelos participantes como passivos de melhorias, cabe ressaltar que as oficinas ocorreram no contexto do programa Mais Educação e, portanto, tem sua carga horária prescrita. Contudo, uma forma de melhorar o tempo das atividades seria otimizar o pouco tempo adequando melhor o grau de dificuldade das atividades aos participantes. Em trabalhos futuros, pretende-se apoiar os professores das escolas representadas nas oficinas, na aplicação de oficinas de desenvolvimento de jogos digitais. Esse apoio ocorrerá disponibilizando material em formato de videoaulas para a orientação das oficinas.

\section{Agradecimentos}

Os autores agradecem a CAPES pelo suporte parcial a esta pesquisa, ao Instituto Nacional de Engenharia de Software (INES), ao CNPq, aos integrantes do Laboratório Gamedu.net e, em especial, ao Programa de Pós-Graduação em Sistemas Computacionais - PPgSC/UFRN, por toda infraestrutura oferecida.

\section{Referências}

Mattar, J. (2010) "Games em Educação: Como os nativos digitais aprendem". São Paulo: Editora Pearson Prentice Hall.

Pietruchinski, M. H.; Coelho Neto, J.; Malucelli, A.; Reinehr, S. (2011) "Os jogos educativos no contexto do SBIE: uma revisão sistemática da literatura". In: XXII Simpósio Brasileiro de Informática na Educação - SBIE, p.476-485.

Silva, T. R.; Aranha, E. H. S.; Olivera, W.; Fernandes, K. T.; Lucena, M. J. N. R. (2015) "Investigando dois formatos de videoaulas de programação de jogos digitais para alunos do ensino médio". In: XXI Workshop de Informática na Escola - WIE, p.187196.

Silva, T. R.; Araujo, G. G.; Aranha, E. H. S. (2014) "Oficinas Itinerantes de Scratch e Computação Desplugada para Professores como apoio ao Ensino de Computação um Relato de Experiência". In: XX Workshop de Informática na Escola - WIE, p.380-389.

Schell, J. (2008) “The Art of Game design: A Book of Lenses”. Burlington: Elsevier.

Schuytema, P. (2011) “Design de games: uma abordagem prática”. São Paulo - SP: Cengage Learning. 